\section{LYTACs for the Degradation of Secreted and Membrane Proteins}

Chemistry in

Medicine and Biology

\section{Key words}

lysosome targeting chimeras

LYTACS

protein degradation

lysosome

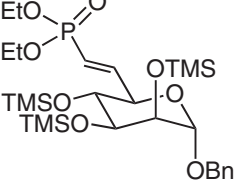

$(\mathrm{EtO})_{2} \stackrel{\mathrm{O}}{\mathrm{P}} \underset{\mathrm{P}}{\mathrm{P}}(\mathrm{OEt})_{2}$

$53 \%$ over 2 steps

Swern oxidation, then

Horner-Wadsworth-Emmons reaction
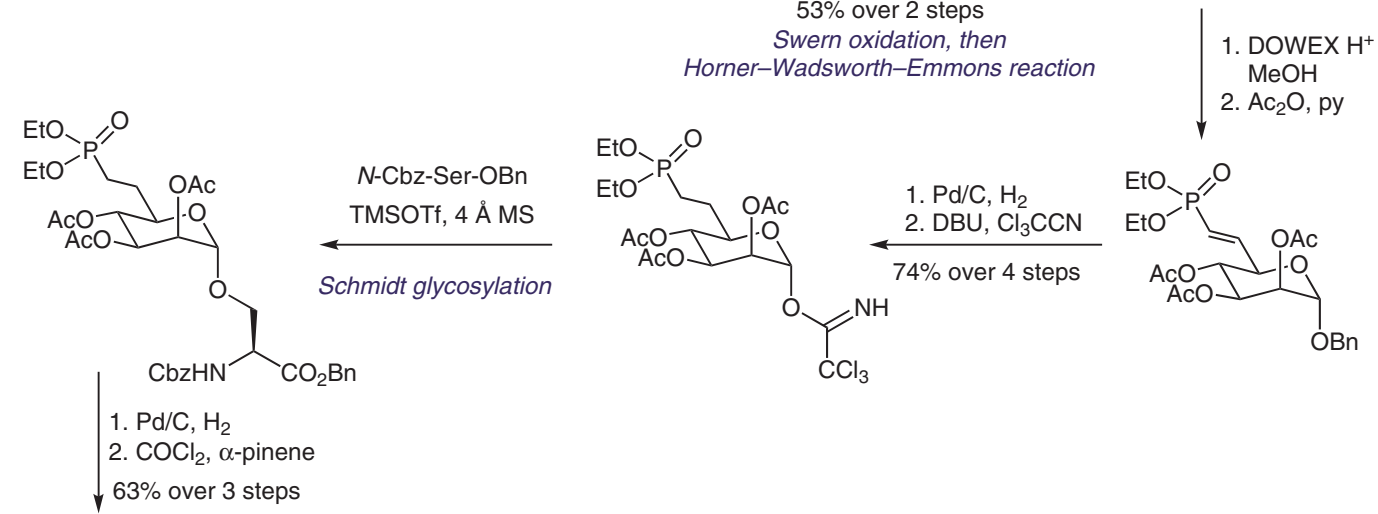
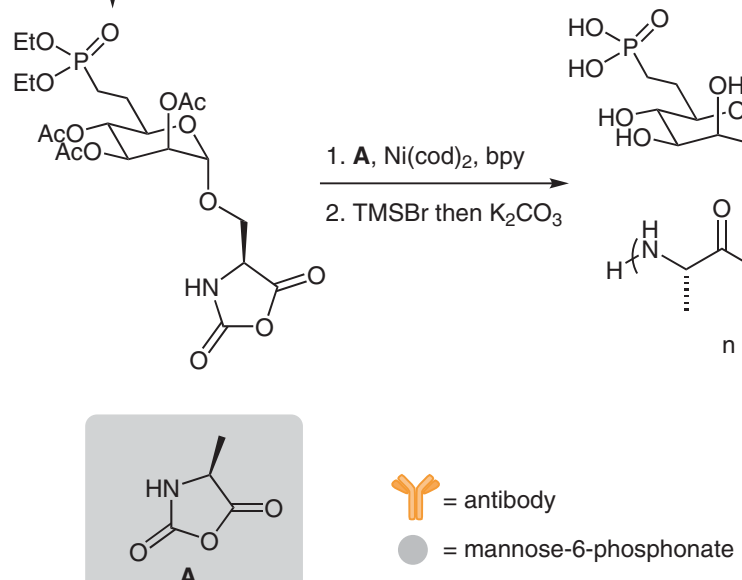

$=$ mannose-6-phosphonate $\begin{gathered}\text { degradation } \\ \text { products }\end{gathered}$

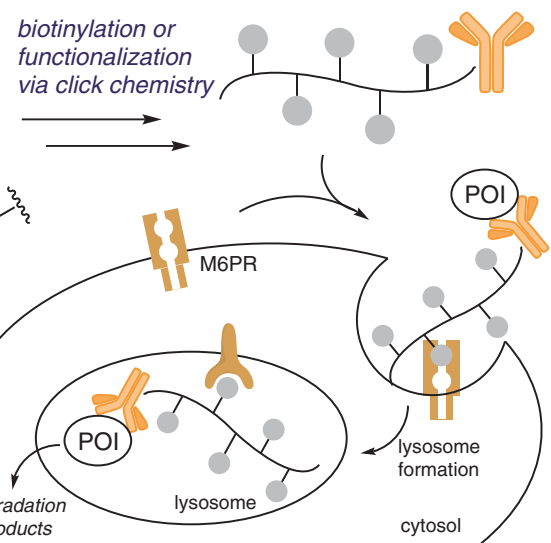

Significance: Lysosomal degradation makes use of cell-surface lysosomal targeting receptors (LTR), which facilitate the transport of proteins into the lysosome. The authors developed so-called LYTACs, which are chimeric molecules that can bind both an extracellular protein and an LTR, allowing for degradation of non-cytosolic proteins of interest in the lysosome. LYTACs are complementary to PROTACs (proteolysis targeting chimeras), which primarily target cytosolic proteins.
Comment: Mannose-6-phosphate receptor M6PR (or IGF2R) recognizes and binds mannose-6-phosphate residues on proteins and transports them to the lysosome for degradation. The LYTACs presented herein use glycopolypeptides of varying length, which can be attached to an antibody for the POI in a modular fashion using click chemistry. The versatile applicability is demonstrated by successfully targeting different extracellular proteins. 